\title{
A randomised clinical trial comparing prednisone and azathioprine in myasthenia gravis. Results of the second interim analysis
}

\author{
MYASTHENIA GRAVIS CLINICAL STUDY GROUP
}

\begin{abstract}
From January 1983 to October 1990, 41 patients with generalised myasthenia gravis were randomly given either prednisone or azathioprine. The main goal was to record the time to the occurrence of the first episode of deterioration.

During a mean follow-up of $\mathbf{3 0}$ months, 21 patients showed deterioration, 12 in the prednisone group and nine in the azathioprine group $(p=0.40)$. No difference was observed between the two groups in muscular score and functional grade, assessed at the end of each treatment year, or in tolerance. Treatment failure occurred in 17 patients, 12 in the prednisone group and five in the azathioprine group ( $p=0.02)$; even after adjustment for imbalances in prognostic features, the failure rate remained 2.8 times higher in the prednisone group than in the azathioprine group $(p=0.5)$. In the patients in whom treatment failed, symptoms were initially more severe than in the others, but the combination of prednisone and azathioprine resulted in clinical improvement, consisting of remission or only minor deficits in half of the patients after two years of treatment. These findings indicate that azathioprine increases treatment response compared with prednisone, although no difference in the duration of improvement was demonstrated. Nevertheless, it appears that the most severe forms of the disease, often resistant to prednisone or azathioprine alone, could benefit from the combination of both drugs.
\end{abstract}

$(\Im$ Neurol Neurosurg Psychiatry 1993;56:1157-1163) Clinical Study Group P Gajdos (Chairman), D Elkharrat (Secretary), $S$ Chevret, $C$ Chastang (Biostatisticians),

J-C Raphaël, F Bolgert, B Eymard, F Woimant, D Morcamp,

$M$ Tournilhac,

M Dupuis (Participants)

Correspondence to: Dr P Gajdos, Service de Réanimation, Hôpital Raymond Poincaré, 104, boulevard Raymond Poincaré, 92380 Garches, France.

Received 17 June 1992 and in revised form 15 March 1993.

Accepted 19 March 1993 with steroids, ${ }^{3-8}$ whereas azathioprine, the immunosuppressive drug most often used, yielded a success rate of 70-90\%.49-11 To maintain such favourable results, all published series indicated that these medications should be continued for many years. Unfortunately, adverse effects are likely to occur. Finally, there is no prospective randomised study available showing the superiority of any of these treatments with regard to their efficacy or side effects. The indications for steroids or immunosuppressants remain empirical and mainly influenced by their respective contraindications.

To define the optimal therapeutic strategy regarding the long term outcome of generalised myasthenia gravis, we compared two strategies using a prospective randomised design. One group received prednisone alone whereas the remaining patients were given azathioprine and prednisone for four months, and then azathioprine alone. A first interim analysis had been performed, using 1 June 1989 as the reference date, which showed similar results in the two treatment groups. ${ }^{12}$ Accrual was terminated in June 1990 mainly because of the lower than expected recruitment rate. Follow up of all patients has been continued.

The results presented are those of the second interim analysis. They are based on 41 patients.

\section{Patients and methods}

Experimental design

The study compared the long term effects of prednisone and azathioprine in patients with myasthenia gravis, who were randomly allocated between these two treatment groups. Because of the delayed response to azathioprine $^{11}$ and of the need for a prompt improvement in symptoms and signs of myasthenia gravis, patients in the azathioprine group with severe disability also received prednisone for the first four months. We speculated that this combination would not influence the main outcome criteria or the long term outcome. If treatment failed (as defined later) after one year in either the prednisone or the azathioprine group, patients were taken off the protocol and they received a combination of the two drugs. This decision was motivated by the observations in many open trials showing 
that major improvements have been brought about by the combination of steroids and immunosuppressants in patients whose disease has not responded to either drug alone. ${ }^{?}$

\section{Criteria for elegibility}

The diagnosis of myasthenia gravis was based on a fluctuating deficit of skeletal or bulbar muscles, associated with seropositivity of antibodies to acetylcholine receptors or with a decremental amplitude of at least $20 \%$ of the fifth summed muscle potential compared with the first, under a $3-5 \mathrm{~Hz}$ stimulation. We included patients with severe myasthenia gravis, severity being defined by the persistence of at least one of the following criteria, despite treatment with cholinesterase inhibitors and correction of eventual aggravating factors: (a) swallowing impairment; (b) respiratory insufficiency requiring mechanical ventilation; (c) functional deficit responsible for discontinuation of occupational activity or important reduction of daily activity for at least one month.

Patients with at least one of the following criteria were excluded: (a) exclusive ocular myasthenia gravis; (b) contraindications to steroids or immunosuppressive drugs; (c) treatment with steroids or immunosuppressants in the past three months; (d) age under 15 or above 75 years; (e) pregnancy.

\section{Initial assessment}

Initial assessment included clinical examination, electromyography and measurement of the acetylcholine receptor titre. Severity of myasthenia gravis was assessed using a myasthenic muscle score (table 1) and a five-grade functional scale, defined as follows: 1 -complete remission; 2-minor symptoms allowing normal activity, except for exertional activity;

Table 1 Muscle strength score

\begin{tabular}{|c|c|}
\hline & Score (points) \\
\hline $\begin{array}{l}\text { Maintain upper limbs horizontall } \\
1 \text { Point per } 10 \mathrm{~s}\end{array}$ & $\begin{array}{r}\text { Max. } 15 \\
\text { Min. } 0\end{array}$ \\
\hline $\begin{array}{l}\text { Maintain lower limbs above bed } \\
1 \text { Point per } 5 \mathrm{~s}\end{array}$ & $\begin{array}{r}\text { on back } \\
\text { Max. } 15 \\
\text { Min. } 0\end{array}$ \\
\hline $\begin{array}{l}\text { Raise head above bed plane, whil } \\
\text { Against resistance } \\
\text { Without resistance } \\
\text { Impossible }\end{array}$ & $\begin{array}{r}10 \\
5 \\
0\end{array}$ \\
\hline $\begin{array}{l}\text { Sit up from lying position } \\
\text { Without help of hands } \\
\text { Impossible }\end{array}$ & $\begin{array}{r}10 \\
0\end{array}$ \\
\hline $\begin{array}{l}\text { Extrinsic ocular musculature } \\
\text { Normal } \\
\text { Ptosis } \\
\text { Double vision }\end{array}$ & $\begin{array}{r}10 \\
5 \\
0\end{array}$ \\
\hline $\begin{array}{l}\text { Eyelid occlusion } \\
\text { Complete } \\
\text { Incomplete } \\
\text { Impossible }\end{array}$ & $\begin{array}{r}10 \\
5 \\
0\end{array}$ \\
\hline $\begin{array}{l}\text { Chewing } \\
\text { Normal } \\
\text { Weak } \\
\text { Impossible }\end{array}$ & $\begin{array}{r}10 \\
5 \\
0\end{array}$ \\
\hline $\begin{array}{l}\text { Swallowing } \\
\text { Normal } \\
\text { Impaired without aspiration } \\
\text { Impaired with aspiration }\end{array}$ & $\begin{array}{r}10 \\
5 \\
0\end{array}$ \\
\hline $\begin{array}{l}\text { Speech } \\
\text { Normal } \\
\text { Nasal } \\
\text { Slurred }\end{array}$ & $\begin{array}{r}10 \\
5 \\
0\end{array}$ \\
\hline
\end{tabular}

3-moderate symptoms allowing occupational or partial daily activity; 4-major disability requiring discontinuation of occupational activity or major reduction of daily activity; and 5-major disability requiring continuous help by others or mechanical ventilation. The myasthenic muscle score and the functional scale were also used to assess patients during follow-up.

\section{Therapeutic schedules}

In the first group, patients received prednisone $1 \mathrm{mg} / \mathrm{kg}$ once daily for one month, subsequently reduced gradually to $0.5 \mathrm{mg} / \mathrm{kg}$ daily by the fifth month. The second dosage was maintained for one month, then progressively reduced to $0.25 \mathrm{mg} / \mathrm{kg}$ daily by the 10th month. This schedule was maintained until the 12th month, and then adapted to the clinical status of each patient. If the patient deteriorated clinically (see below) during steroid reduction, the dosage was doubled within an upper limit of $1 \mathrm{mg} / \mathrm{kg}$ daily. After one month at this dosage, reduction was resumed in order to reach, within two months, 5-10 $\mathrm{mg}$ above the level at which the clinical deterioration occurred. If treatment failed, azathioprine was added at a dosage of $3 \mathrm{mg} / \mathrm{kg}$ daily for one year, and then $2 \mathrm{mg} / \mathrm{kg}$.

In the second group, patients received azathioprine $3 \mathrm{mg} / \mathrm{kg}$ once daily for one year, then $2 \mathrm{mg} / \mathrm{kg}$ daily. Because of the delayed response to azathioprine, ${ }^{11}$ patients were also given prednisone at a daily dosage of $1 \mathrm{mg} / \mathrm{kg}$ during the first month. Thereafter, prednisone was progressively tapered off and then discontinued at the end of the fourth month. If the treatment failed, prednisone was introduced again at a dosage of $1 \mathrm{mg} / \mathrm{kg}$ daily for one month and then reduced as described in the first group.

In addition all patients received cholinesterase inhibitors (pyridostigmine or ambemonium). If swallowing was impaired or respiratory insufficiency was observed, whichever group the patient was in, the investigator was allowed to use therapeutic plasma exchanges during the first two weeks. Such plasma exchange treatment, however, had to be decided before randomisation.

The protocol was approved by the Ethics Committee of the Société de Réanimation de Langue Française (Paris, France). Patients were informed, but no written consent was required according to French regulations in effect at the time.

\section{Randomisation}

Randomisation was performed through a centralised telephone, blind assignment procedure with blocks of four patients, stratified by centre and according to whether or not patients had had a thymectomy.

The trial was not blind, because the side effects of each treatment would have led inevitably to their identification.

\section{Endpoints}

Owing to the experimental design, we looked 
for endpoints that would not be altered by the possible combination of the two tested drugs. As the protocol consisted of prednisone at high dosage and possibly plasma exchange treatment within the first weeks in both randomised groups, we speculated that most of the patients would improve during the first months. We then hypothesized that the maintenance or the progression of this improvement would differ according to whether patients were subsequently maintained on either prednisone or azathioprine alone.

The main endpoint was the time that elapsed to the first episode of meaningful, clinical deterioration within the 60 months, assessed from the date of treatment onset. Such a deterioration was defined by the occurrence of either impaired swallowing or respiratory insufficiency, or a drop in the myasthenic muscle score of at least 20 points.

Treatment failure within 60 months was analysed as a secondary endpoint. It was defined as an increase of less than two grades in the functional scale after one year of treatment, or by the occurrence of two episodes of clinical deterioration, as described above.

Other endpoints, possibly influenced by the combination of the two drugs, were also analysed, namely the functional grade and the myasthenic muscle score at the end of each treatment year and, finally, the overall rate of side effects.

\section{Follow up}

Examinations were scheduled for the second, fourth, sixth, ninth and 12 th month and every six months thereafter. Clinical evaluation included assessment of the muscle score and the functional grade. All side effects were listed: cushingoid feature; bacterial, viral or fungal infection; systemic hypertension; diabetes; osteoporosis; psychiatric problems; hair loss; decrease in polymorphonuclear cell or platelet counts below $1500 / \mathrm{mm}^{3}$ and $150000 / \mathrm{mm}^{3}$, respectively; and an increase in alanine or aspartate transaminases and alkaline phosphatase above two upper limits.

Estimation of sample size and statistical methods The estimation of sample size was based on the method described by George and Desu. ${ }^{13}$ With an assumption of treatment benefit

Table 2 Main clinical features of patients in the two groups at the time of randomisation

\begin{tabular}{|c|c|c|c|}
\hline & $\begin{array}{l}\text { Prednisone } \\
(n=20)\end{array}$ & $\begin{array}{l}\text { Azathioprine } \\
(n=21)\end{array}$ & $p$ value ${ }^{\star}$ \\
\hline $\begin{array}{l}\text { Male } \\
\text { Age (years) } \\
\text { Duration of disease (years) } \\
\text { Number of previous crises } \\
\text { Thymectomy } \\
\text { Thymoma } \\
\text { Myasthenic muscle score } \\
\text { Functional scale } 2 \\
3 \\
4 \\
5 \\
\text { AChR-ab titre } 10^{-9} \mathrm{M} \\
\text { AChR-ab undetectable } \\
\text { Therapeutic plasma exchange }\end{array}$ & $\begin{aligned} & 7(35 \%) \\
& 47(20) \\
& 4 \cdot 7(6 \cdot 8) \\
& 1 \cdot 7(2 \cdot 6) \\
& 12(60 \%) \\
& 7(35 \%) \\
& 47(19) \\
& 0 \\
& 7 \\
& 6 \\
& 7 \\
& 90(143) \\
& 3(15 \%) \\
& 12(60 \%)\end{aligned}$ & $\begin{array}{c}8(38 \%) \\
43(17) \\
6(7 \cdot 2) \\
1 \cdot 9(1 \cdot 8) \\
11(52 \%) \\
3(15 \%) \\
54(21) \\
1 \\
8 \\
8 \\
4 \\
216(240) \\
6(29 \%) \\
7(33 \%)\end{array}$ & $\begin{array}{l}0.84 \\
0.65 \\
0.85 \\
0.40 \\
0.62 \\
0 \cdot 16^{\star \star} \\
0 \cdot 29 \\
\\
0.54 \\
0 \cdot 10 \\
0.45^{\star \star} \\
0.12\end{array}$ \\
\hline
\end{tabular}

For continuous variables, mean (SD) is given.

$\star \chi$ square test for categorical variables, non parametric Wilcoxon test for continuous variables.

AChR-ab = antibodies to acetycholine receptors. given by a decrease in one year deterioration rate from $75 \%$ with prednisone to $50 \%$ with azathioprine, errors of $a=0.05$ and $\beta=0.10$ for a two-sided test, it was decided that 105 patients had to be recruited.

Statistical analysis was performed on an intention-to-treat basis. Failure time estimates (time to clinical deterioration and time to treatment failure) were based on the Kaplan-Meier method, ${ }^{14}$ then compared between the randomised groups by the log rank test. ${ }^{15}$ The semiparametric Cox's model ${ }^{16}$ was used to adjust treatment comparison of both imbalanced and prognostic baseline variables.

Comparison of side effects in the two treatment groups was based on Fischer's test of exact probability, whereas the comparison of functional grades and myasthenic muscle scores at each year were based on the nonparametric Wilcoxon's test.

The findings at the reference date of 1 October 1990 were used.

\section{Results}

From January 1983 to June 1990, 41 patients with myasthenia gravis were recruited in the six neurological departments of the Myasthenia Gravis Clinical Study Group and were randomly allocated to receive either prednisone (20 patients) or azathioprine (21 patients). At the reference date of October 1990, the mean follow-up was 30 months and no patient was lost to follow-up.

Table 2 presents the main characteristics of the two treatment groups at the time of randomisation. Although there are some imbalances (more thymectomies in the prednisone group, higher acetylcholine receptor levels in the azathioprine group), this table shows no major differences in the distribution of baseline parameters in the two treatment groups. Nineteen patients received therapeutic plasma exchanges, namely 12 in the prednisone group and seven in the azathioprine group, but the difference was not statistically significant ( $p=0.12, \chi$-square test). The total number of plasma exchanges administered did not differ between the two groups (median 3.5 $v 3$ ).

Figure 1 shows the time to first occurrence of clinical deterioration. Among the 21 deterioration events, 12 were observed in the prednisone group and nine in the azathioprine group ( $p=0.40$, two-sided log rank test). During the two first years of treatment, the deterioration rate was estimated at $52 \%$ in the prednisone group as opposed to $37 \%$ in the azathioprine group. The four year deterioration rate was estimated at $67 \%$ and $51 \%$, respectively.

Otherwise, the treatment failure rate was higher, although not statistically significant, in the prednisone group $(60 \%)$ than in the azathioprine group (24\%) $(p=0 \cdot 15, \chi$-square test). Moreover, treatment failures were delayed in the azathioprine group compared with the prednisone group $(p=0.02$, twosided log rank test; fig 2). For instance, the 
$\%$ free of deterioration

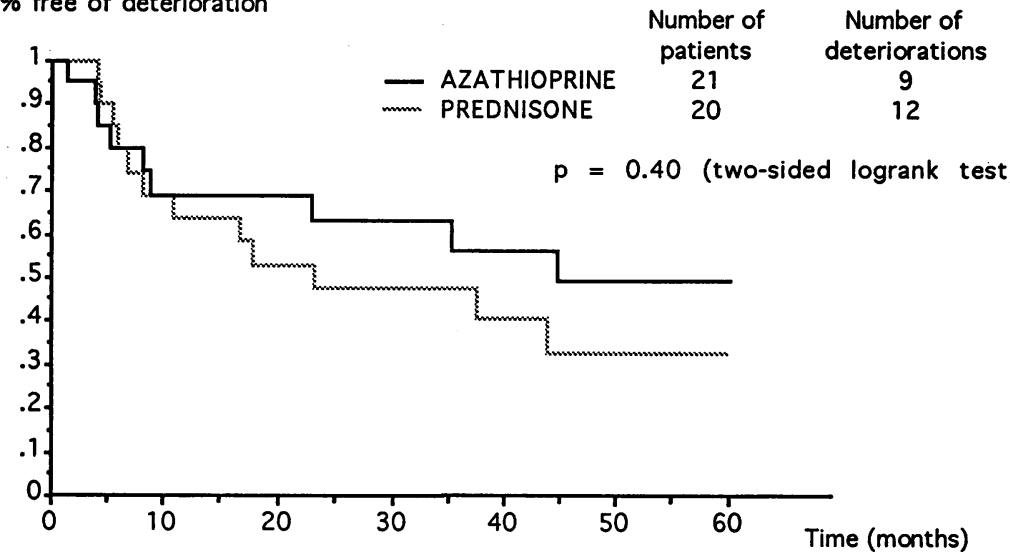

Figure 1 Time to occurrence of clinical deterioration according to randomisation.

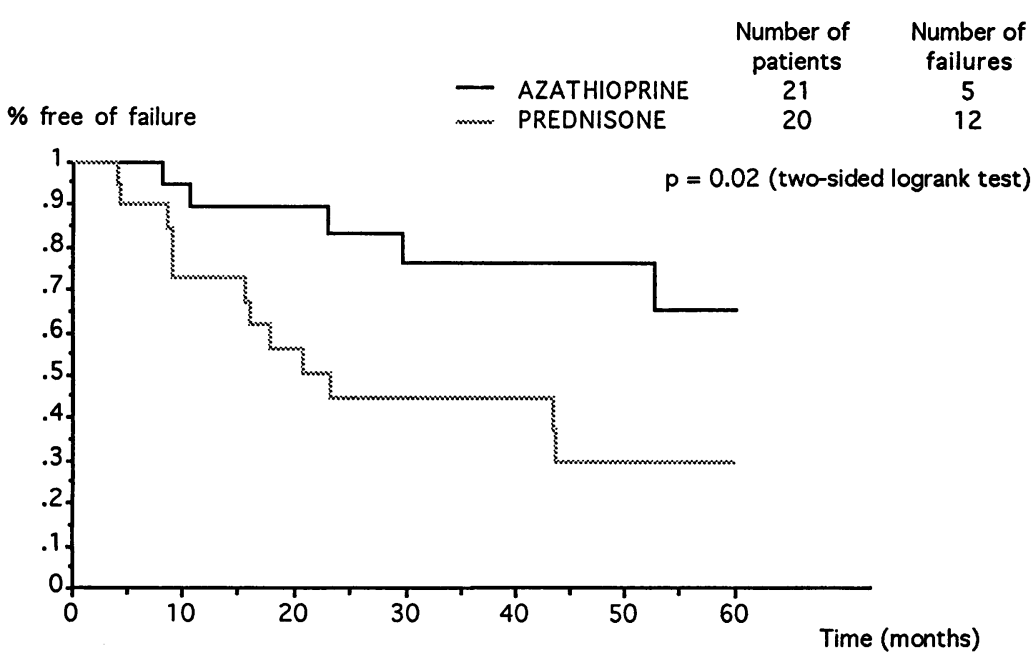

Figure 2 Time to occurrence of treatment failure according to randomisation.

12 month failure rate was estimated at $27 \%$ in the prednisone group and $11 \%$ in the azathioprine group. Treatment comparison was thereafter adjusted on prognostic factors, using Cox's model, to remove imbalances against the azathioprine group (higher mean muscle score and antibody titre) and to cor- rect the bias in estimating the treatment effect caused by omitting a balanced prognostic factor when considering a censored criterion such as time to treatment failure. Three parameters were selected as either being imbalanced between the two randomised groups (table 2) or as being individually predictive for treatment failure, as assessed by the log rank test (table 3). They consisted of initial myasthenic muscle score, functional grade, and time from disease onset. As for the unadjusted test, the adjusted treatment comparison for treatment failure still showed a significantly longer time to treatment failure in the azathioprine group $(p=0.05$, twosided likelihood ratio test); the adjusted failure rate was estimated to be 2.8 times higher in the prednisone group than in the azathioprine group.

According to the protocol, the 17 patients whose treatment failed were subsequently treated with the combination of prednisone and azathioprine. Therefore, observed changes either in myasthenic muscle score or in the functional grade during the follow up could be incurred by either the randomised treatment or the combination of prednisone and azathioprine. According to the intentionto-treat analysis, no differences were observed between the prednisone or the azathioprine groups in the myasthenic muscle score at the end of each year (fig 3). Changes in functional scale were similar in both treatment groups. At the end of the first year of treatment, and according to the functional scale described above, $72 \%$ in the prednisone group and $74 \%$ in the azathioprine group were in remission (grade 1) or had a minor deficit (grade 2). At the end of the second year, these figures were $65 \%$ and $76 \%$, respectively, and at the end of the third year, there were $67 \%$ and $64 \%$. Among the patients who failed to respond to either prednisone or azathioprine alone, eight out of 16 and five out of 11 were in remission or had a

Table 3 Prognostic value, assessed by the log rank test, of several baseline parameters, for either treatment failure or deterioration

\begin{tabular}{|c|c|c|c|c|c|}
\hline Variables & $\begin{array}{l}\text { Number of } \\
\text { patients } \\
(n=41)\end{array}$ & $\begin{array}{l}\text { Number of } \\
\text { deteriorations } \\
(n=21)\end{array}$ & $\begin{array}{l}\text { p value* } \\
\text { (log rank) }\end{array}$ & $\begin{array}{l}\text { Number of } \\
\text { failures } \\
(n=17)\end{array}$ & $\begin{array}{l}\text { p value }{ }^{\star *} \\
\text { (log rank) }\end{array}$ \\
\hline \multicolumn{6}{|l|}{ Randomisation } \\
\hline Azathioprine & 21 & 9 & 0.40 & 5 & 0.02 \\
\hline \multirow{2}{*}{\multicolumn{6}{|c|}{ Sex }} \\
\hline & & & & & \\
\hline $\begin{array}{l}\text { Male } \\
\text { Female }\end{array}$ & $\begin{array}{l}15 \\
26\end{array}$ & $\begin{array}{r}8 \\
13\end{array}$ & 0.57 & $\begin{array}{l}8 \\
9\end{array}$ & $0 \cdot 12$ \\
\hline \multicolumn{6}{|l|}{ Age (years) } \\
\hline $\begin{array}{l}\leqslant 40 \\
>40\end{array}$ & $\begin{array}{l}19 \\
22\end{array}$ & $\begin{array}{l}10 \\
11\end{array}$ & $0 \cdot 71$ & $\begin{array}{l}8 \\
9\end{array}$ & $0 \cdot 78$ \\
\hline \multicolumn{6}{|l|}{ Previous crisis } \\
\hline $\begin{array}{l}\text { No } \\
\text { Yes }\end{array}$ & $\begin{array}{l}11 \\
30\end{array}$ & $\begin{array}{r}5 \\
16\end{array}$ & 0.95 & $\begin{array}{r}6 \\
11\end{array}$ & $0 \cdot 12$ \\
\hline \multicolumn{6}{|c|}{ Time from disease onset (years) } \\
\hline $\begin{array}{l}\leqslant 5 \\
>5\end{array}$ & $\begin{array}{l}29 \\
12\end{array}$ & $\begin{array}{r}16 \\
5\end{array}$ & $0 \cdot 48$ & $\begin{array}{r}15 \\
2\end{array}$ & 0.08 \\
\hline \multicolumn{6}{|l|}{ Thymectomy } \\
\hline $\begin{array}{l}\text { No } \\
\text { Yes }\end{array}$ & $\begin{array}{l}18 \\
23\end{array}$ & $\begin{array}{r}9 \\
12\end{array}$ & 0.67 & $\begin{array}{l}8 \\
9\end{array}$ & 0.62 \\
\hline \multicolumn{6}{|l|}{ Muscle strength } \\
\hline $\begin{array}{r}\text { score } \leqslant 50 \\
>50\end{array}$ & $\begin{array}{l}22 \\
19\end{array}$ & $\begin{array}{r}14 \\
7\end{array}$ & 0.02 & $\begin{array}{r}11 \\
6\end{array}$ & 0.06 \\
\hline Stage $\frac{1-4}{5}$ & $\begin{array}{l}30 \\
11\end{array}$ & $\begin{array}{r}12 \\
9\end{array}$ & 0.0004 & $\begin{array}{r}11 \\
6\end{array}$ & 0.06 \\
\hline
\end{tabular}

ᄎ The $\mathrm{p}$ value of the log rank test comparing the occurrence of clinical deteriorations between the groups defined by the presence or absence of several baseline characteristics.

$\star \star T$ The $p$ value of the log rank test comparing the occurrence of treatment failures between the groups defined above. 

myasthenic muscle score (median) in the two randomised groups.
Figure 3 Evolution of the

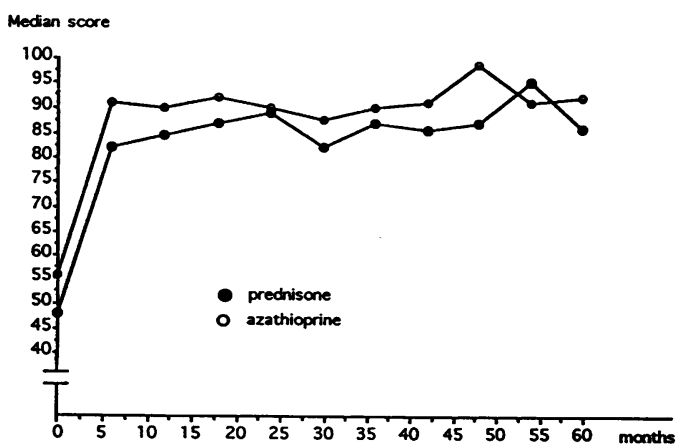

minor deficit respectively after one and two years of treatment with prednisone plus azathioprine.

Table 4 lists all the adverse effects observed during the follow up. Sixty-seven side effects were recorded from 28 patients. The percentage of patients who experienced at least one side effect was higher in the prednisone group ( $80 \%)$ than in the azathioprine group $(57 \%)$, although this was not statistically significant ( $p=0 \cdot 18$, two-sided Fisher's test). After excluding the 14 observed cushingoid features, including 11 in the prednisone group and three in the azathioprine group, these percentages dropped to $45 \%$ and $43 \%$, respectively $(p=1.00$, two-sided Fisher's test). The percentage of patients who developed at least one bacteriological infection was significantly higher, however, in the prednisone group compared with the azathioprine group ( $p=0.05$, two-sided Fisher's test). In the prednisone group, 12 bacterial infectious episodes were observed in 10 patients, as opposed to four infections in the azathioprine group. Among these bacterial infections there were seven cases of pneumonia (five in the prednisone group and two in the azathioprine group) which yielded a deterioration of the myasthenia and acute respiratory failure in four cases (three in the prednisone group, one in the azathioprine group). The other bacterial complications included urinary tract infections and skin infections which did not affect

Table 4 Total side effects observed in the prednisone group and in the azathioprine group

\begin{tabular}{|c|c|c|c|}
\hline & $\begin{array}{l}\text { Prednisone } \\
(n=20)\end{array}$ & $\begin{array}{l}\text { Azathioprine } \\
(n=21)\end{array}$ & \multirow{3}{*}{$\begin{array}{l}\text { p value } \\
\text { (Fisher's test) } \\
0 \cdot 18\end{array}$} \\
\hline & \multicolumn{2}{|c|}{$\begin{array}{l}\text { Number of patients with at least one } \\
\text { side effect }\end{array}$} & \\
\hline & $16(80 \%)$ & $12(57 \%)$ & \\
\hline \multirow{2}{*}{\multicolumn{4}{|c|}{ Side effects }} \\
\hline Cushingoid features & 11 & & 0.009 \\
\hline Bacterial infection & 10 & 4 & 0.05 \\
\hline Viral infection & 0 & 4 & 0.11 \\
\hline Fungal infection * & 3 & 3 & 1.00 \\
\hline Systemic hypertension $\dagger$ & 2 & 1 & 0.61 \\
\hline Diabetes & 2 & 0 & $0 \cdot 23$ \\
\hline Osteoporosis & 6 & 2 & 0.13 \\
\hline Psychiatric disorders $\ddagger$ & 1 & 0 & $0 \cdot 49$ \\
\hline Hair loss & 4 & 2 & 0.41 \\
\hline Polymorphonuclear cell & 1 & 3 & 0.61 \\
\hline ASAT or ALAT increase & 0 & 4 & $0 \cdot 11$ \\
\hline Alkaline phosphatase increase & 0 & $i$ & 1.00 \\
\hline Total & 40 & 27 & \\
\hline
\end{tabular}

^Buccal or cutaneous infections.

†Defined by diastolic blood pressure above $100 \mathrm{~mm} \mathrm{Hg}$.

$\ddagger$ Psychotic episode. the course of the myasthenia. Four viral infections were otherwise observed in the azathioprine group: one herpes zoster, one herpes gengivostomatitis and two cases of pneumonia. Finally, in the azathioprine group, treatment was discontinued after the occurrence of hepatitis in two patients, who both recovered without sequelae. A drop in polymorphonuclear cell count below $1500 / \mathrm{mm}^{3}$ was observed in four patients; it consistently returned to normal after transient discontinuation or reduction in azathioprine dosage. In the prednisone group, treatment was discontinued in one patient because of bilateral rupture of the Achilles tendon.

\section{Discussion}

Immunosuppressive drugs and steroids are now widely used in the treatment of severe mysthenia gravis, achieving long term improvement and increased remission rates. The second analysis of our trial confirms the good outcome of such patients, in both treatment groups. Indeed, muscle strength improved and remained stable over several years in most patients, reflected by the course of the myasthenic muscle score. After the first year of treatment, about $70 \%$ of patients were in complete remission or showed a minor deficit. These results are in agreement with those of Cornelio et al $^{7}$ who reported $72 \%$ remission or minor deficit after a follow up ranging from 18 months to six years in patients with myasthenia gravis treated with prednisone, azathioprine, or their combination.

Our findings suggested a beneficial effect from azathioprine, compared with prednisone, when given in a daily regimen to patients with severe myasthenia gravis. Although no significant difference regarding the time to occurrence of first clinical deterioration was demonstrated, treatment failures were more frequently seen and observed earlier in the prednisone group (with a one year failure rate of $27 \%$ ) compared with the azathioprine group (with a one year rate of $11 \%)$. Otherwise, although time to clinical worsening appeared to be similar in both treatment groups, there was a trend that azathioprine could do better, with the two year deterioration rate estimated at $37 \%$ in the azathioprine group compared with $52 \%$ in the prednisone group. Such a trend was observed despite the low power of the treatment comparison. Indeed for a two-sided test and for $a=0.05$, the power was $34 \%$ to detect a change in one year deterioration from $75 \%$ (assumed one year deterioration in the prednisone group) to $50 \%$. Such estimates were not confirmed in our sample, however, given that the observed one year deterioration rates were $36 \%$ in the prednisone group and $31 \%$ in the azathioprine group. Obviously, the required sample size to detect such a slight difference was larger than that planned. Moreover, the required sample size was not reached. This could be explained by the low prevalence of the disease, about 60 
per million. ${ }^{2}$ The very restrictive criteria for eligibility also could have contributed to a very low inclusion rate. This led the Myasthenia Gravis Clinical Study Group to decide, on June 1990, to stop randomisation. Follow up of all 41 recruited patients has been continued ever since. Finally, it must be noted that about $44 \%$ of the patients effectively received a combination of the two tested treatments from one year after randomisation, in agreement with the protocol, and this could have erased the eventual difference between the two treatment groups in terms of either muscular score or functional grade. Obviously, it would not have been ethical to deprive patients who did not respond to either prednisone or azathioprine from the potential benefits expected from their combination. It is noteworthy that such patients, in whom neither prednisone or azathioprine was successful, initially had a more severe myasthenia in terms of both muscular score and functional grade, than those who improved (table 3 ). In $45 \%$ of these single treatment failures, however, the introduction of combined prednisone and azathioprine resulted in remission or only minor deficits two years later. A similar outcome was reported by Cornelio et al $^{7}$ who observed $32 \%$ remission and $48 \%$ improvement with the combination of prednisone and azathioprine in 25 patients who did not respond to either drug when given alone. The superiority of the combination over prednisone alone has also been suggested in the treatment of other immune diseases such as lupus nephritis. ${ }^{17}$

Nevertheless, the difference in the failure rate between the prednisone and azathioprine groups should be interpreted with caution. Firstly, treatment allocation was not blind, because it could not have been maintained given the specific side effects of each treatment. This may have induced some investigators to recognise failure more often in the prednisone group. Secondly it must be noted that, although the azathioprine failure rate estimated from our series is in agreement with previous reports by Mertens $e t a l$ and Mattell, ${ }^{11}$ the estimated prednisone failure rate appears higher than that usually attributed to steroids. Using steroids, Johns ${ }^{8}$ reported an $80 \%$ remission or major improvement rate in 116 myasthenic patients, and Sghirlanzoni et al a $72 \%$ improvement rate in 60 myasthenic patients. Nevertheless, treatment failures observed in our prednisone group did not seem to be related to a precipitous decrease in dosage, as the mean daily dosage of prednisone was 27 (10) $\mathrm{mg}$ (range: 15-50 mg daily) when the absence of improvement was observed. Neither did the failures seem to be related to an insufficient length of treatment, as the duration was over one year in 11 of 13 patients of this group. Two patients had been treated for four months with prednisone when it was concluded that they were not responding adequately. Clinical status was unchanged in one and worsened in the other during prednisone treatment. Rowland, ${ }^{4}$ in a review of published reports, stated that improvement with steroids usually occurs before the 50th day. In Johns's series, ${ }^{8} 93$ patients out of 116 improved with prednisone before the 60th day. Finally, the high failure rate observed in the prednisone group could not be explained by a difference in severity of the disease between the two groups. Indeed, after using Cox's model to adjust for three baseline prognostic factors, namely myasthenic muscular score, functional scale, and time from disease onset, the failure rate was still estimated to be 2.8 times higher in the prednisone group.

Finally, the overall percentage of patients who have experienced at least one side effect was similar in both groups. Several side effects were more frequently observed in the prednisone group, however, such as cushingoid features-as expected-and, more surprisingly, bacterial infections. Moreover, the respective influence of azathioprine and prednisone in the occurrence of these adverse effects may be difficult to analyse, given that all patients received both drugs at the beginning of treatment and that 18 patients $(44 \%)$ were secondarily treated with the combination. In three patients (one in the prednisone group, and two in the azathioprine group), side effects were responsible for the discontinuation of the involved drug. As reported in other series, ${ }^{11} 1819$ haematological side effects and increase of hepatic enzymes consistently returned to normal after reduction or transient interruption of azathioprine. Unfortunately, long term side effects of azathioprine have not yet been assessed in our study. Nonetheless, few severe long term side effects have been reported in the literature. In a series of 104 patients followed up for 12 years. Hohlfeld et $a l^{18}$ reported a single case of renal lymphoma which may have been brought about by the administration of azathioprine. Corey, ${ }^{20}$ after reviewing five published studies of 800 patients treated with azathioprine, found one case of acute leukemia and no lymphoma.

In conclusion, this randomised clinical trial in patients with severe myasthenia gravis failed to show any marked benefit in either the duration of improvement or treatment tolerance from azathioprine in a daily regimen, when compared with prednisone. Nevertheless, this trial showed that azathioprine increases treatment response and that, whatever the treatment group, the occurrence of treatment failure depends mainly on the initial severity of the disease. Given that $50 \%$ of these severe forms improved with the combination of both treatments, the question is posed of whether the combination of prednisone and azathioprine should be proposed first in the management of severe myasthenia gravis. A randomised trial comparing the effects of prednisone alone versus the combination of prednisone and azathioprine is thus warranted.

This work was supported by the Association Française contre les Myopathies (AFM). 
1 Grob D, Arsura EL, Brunner NG, Namba T. The course of myasthenia gravis and therapies affecting outcome. In: Drachman B, ed. Mysthenia gravis. Biology and treatment. Ann N Y Acad Sci 1987;505:472-99.

2 Oosterhuis HJ. Myasthenia gravis. New York: Churchill Livingstone, 1984.

3 Sanders DB, Howard FJ, Johns TR, Campa JF. High dose daily prednisone in the treatment of myasthenia gravis. In: Dau P, ed. Plasmapheresis and the immunobiology of myasthenia gravis. Boston: Houghton Mifflin, 1979: 289-306.

4 Rowland LP. Controversies about the treatment of myasthenia gravis. $\mathcal{f}$ Neurol Neurosurg Psychiatry 1980;43. 644-59.

5 Pascuzzi RM, Coslett HB, Johns TR. Long term corticosteroid treatment of myasthenia gravis. Ann Neurol 1984;15:291-8.

6 Sghirlanzoni A, Peluchetti D, Mantegazza R, Fiacchino F, Cornelio F. Myasthenia gravis: prolonged treatmen with steroids. Neurology 1984;34:170-4.

7 Cornelio F, Peluchetti D, Mantegazza R, Sghirlanzoni A Collarile $C$. The course of myasthenia oravis in patients treated with corticosteroids azathioprine and plasmatreated pheresis. In: Drachman B, ed. Myasthenia gravis. 5iology

8 Johns TR. Long term corticosteroid treatment of myasthenia gravis. In: Drachman B, ed. Myasthenia gravis. Biology and
505:568-83.

9 Mertens HG, Hertel G, Reuther P. Ricker K. Effect of immunosuppressive drugs (azathioprine). In: Grob D, ed. Myasthenia gravis. Pathophysiology and management. Ann N Y Acad Sci 1981;377:691-8.

10 Witte AS, Cornblath DR, Parry EJ, Lisak RP, Schatz NJ.
Azathioprine in the treatment of myasthenia gravis. Ann Neurol 1984;15:602-5.

11 Matell G. Immunosuppressive drugs: azathioprine in the treatment of myasthenia gravis. In: Drachman B, ed. Myasthenia gravis. Biology and treatment. Ann N Y Acad Sci 1987;505:588-94.

12 Gajdos $\mathrm{Ph}$, Elkharrat $\mathrm{D}$, Chastang CL. Comparison of the effects of prednisone versus azathioprine on the treatment of pryasthenia Preliminary results of a prospective study. 2nd European Conference on myasthe-

nia gravis. Tremezzo, 1989.

George SL, Desu MM. Planning the size and duration of a clinical trial studying the time to some critical event. Chron Dis 1974;87:15-24.

14 Kaplan E, Meier P. Non parametric estimation for incomplete observation. $\mathcal{f} \mathrm{Am}$ Stat Assoc 1958;53:457-81.

15 Peto R, Peto J. Asymptotically efficient rank invariant test procedures (with discussion). $\mathcal{F}$ Stat Soc 1972; A 135:185-206.

16 Cox DR. Regression models and life-tables (with discussion). $\mathcal{F} R$ Stat Soc 1972;B 34:187-220.

17 Felson DT, Anderson J. Evidence for the superiority of immunosuppressive drugs and prednisone over prednisone alone in lupus nephritis. Results of a pooled analysis. New Engl $\mathcal{F} M$ Med 1984;311:1528-33.

18 Hohlfeld R, Michels M, Heininger K, Besinger U, Toyka $\mathrm{KV}$. Azathioprine toxicity during long-term immunosuppression of generalized myasthenia gravis. suppression of gener

19 Fonseca V, Havard CWH. Long term treatment of myasthenia gravis with azathioprine. Postgrad Med F 1990; 66:102-5.

20 Corey A. General discussion on therapy in Myasthenia Gravis. In: Drachman B, ed. Myasthenia gravis. Biology and treatment. Ann N Y Acad Sci 1987;505:609. 